\title{
Predicting creep-fatigue crack growth rates in Alloy 709 using finite element simulations of plasticity and creep-induced crack closure
}

\author{
Jose Ramirez ${ }^{1}$, Gabriel P. Potirniche ${ }^{1 *}$, Henry Pugesek $^{1}$, Nicholas Shaber ${ }^{1}$, Martin Taylor ${ }^{2}$, Robert Stephens ${ }^{1}$, Indrajit Charit $^{2}$. \\ ${ }^{1}$ Mechanical Engineering Department, University of Idaho, 875 Perimeter Drive MS 0902, Moscow, ID 83844-0902, USA \\ ${ }^{2}$ Chemical and Materials Engineering Department, University of Idaho, 875 Perimeter Drive MS 3024, Moscow, ID 83844-0902, USA
}

\begin{abstract}
This paper reports on a computational study and experimental validation of creep-fatigue crack growth rates at high temperature in two structural materials. The objectives are to develop a methodology to predict creep-fatigue crack growth rates using plasticity-induced crack closure under creep-fatigue loading conditions by characterizing the effect of hold time on crack growth rates during cyclic loading. In this study, the computation of fatigue crack growth rates is based on the crack closure phenomenon. The total crack growth rate during creep-fatigue loading is based on the addition of fatigue crack growth rate during cyclic loading and creep crack growth rate during hold time. The study identifies the effects of frequency and shape of loading cycle on crack-tip opening stresses induced by the combined action of the plasticity-induced crack closure and creep relaxation at the crack tip. Two-dimensional finite element analyses of compact tension specimens are performed to simulate crack growth under cyclic and time-dependent loading conditions. Elastic-plastic-creep material behavior is considered in these simulations. Closure levels are computed for high temperature structural materials such as $9 \mathrm{Cr}-1 \mathrm{Mo}$ steel and Alloy 709. The numerical predictions provide satisfactory agreement with experimental data of creep-fatigue crack growth rates in modified $9 \mathrm{Cr}-1 \mathrm{Mo}$ and Alloy 709 steels at high temperatures.
\end{abstract}

\section{Introduction}

Innovative structural materials are a keystone in improving the design and development of advanced energy systems. The performance of advanced energy systems, hereby advanced nuclear reactors, require that structural materials to be employed in advanced reactor components go through critical stages of development and qualification. In order to ensure adequate performance of these components in service and under extreme conditions, these materials must push the current boundaries of in-service conditions, namely, elevated temperatures and long service life expectations. Furthermore, selected materials must provide greater safety margins and facilitate the implementation of challenging designs while simultaneously leading to the reduction of capital costs and ensuring structural integrity [1].

Sodium Fast Reactor (SFR) is a leading concept and promising candidate in the U.S. power sector to reduce $\mathrm{CO}_{2}$ emissions and to make nuclear energy production more efficient and sustainable. The design, construction, and operational costs associated with these advanced reactors are highly dependent on the selected high temperature structural materials. Alloy 709 is an advanced heat and corrosion resistant austenitic stainless steel derived from the original $\mathrm{Nb} / \mathrm{Ti}$ stabilized $\mathrm{Fe}-20 \mathrm{Cr}-25 \mathrm{Ni}-$ $1.5 \mathrm{Mo}-\mathrm{Nb}(\mathrm{NF} 709$ ) steel. Due to its superior creep resistance compared to conventional 304 and 316 stainless steels, and due to the cost to produce it, which is estimated to be 2 to 4 times that for $304 \mathrm{SS}$, and far below the cost of Ni-based superalloys with comparable strength [2], alloy 709 was down-selected as a candidate material for structural applications, namely, for reactor vessels, core supports, and primary and secondary piping components in SFRs.

Creep-fatigue (CF) is a dominant loading mode expected in fast reactor structural materials. Fatigue and CF characterization are necessary to construct the creepfatigue interaction diagram required to build the future code case submittal for alloy 709. In this regard, structural integrity assessment of these power generation components requires rigorous creep-fatigue crack growth characterization and predictive computational models for the creep-fatigue crack growth behavior that takes into account creep-fatigue interactions in Alloy 709 at temperatures between $600^{\circ} \mathrm{C}$ and $700^{\circ} \mathrm{C}$.

\section{Plasticity-induced crack closure}

The relevance of plasticity-induced crack closure (PICC) on fatigue crack growth was first identified experimentally by Elber [3]. Since then, numerous developments on fatigue crack growth modeling have been performed. In this work, it was revealed that the

\footnotetext{
* Corresponding author: gabrielp@uidaho.edu
} 
fatigue crack closure phenomenon was observed along the crack faces due to permanent plastic deformation in the wake of a propagating crack. Moreover, it was observed that a propagating crack in a fatigue specimen is completely open only for a portion of the loading cycle. The main implication of this observation is that the crack faces of a growing crack contact each other even before reaching the minimum load during the unloading portion of a cycle. This premature contact generates stresses that reduce the effective stress intensity factor at the crack tip, decreasing the crack advance rate. Several crack closure mechanisms were revised in detail in [4], and the possibility of a synergistic operation of these mechanisms was also considered. However, it has been established that in engineering problems, the main contribution to fatigue crack closure is material plasticity due to the existence of compressive zones at the crack tip, and the plastic wake generated by permanently deformed material along the crack faces [5].

Two prior studies have been identified in the area of finite element computation of crack closure levels with hold periods in high temperature fatigue crack growth [6, 7], and only Pommier et al. [7] computed crack growth rates based on measured crack-tip opening stresses. Therefore, in this study, the proposed model aims at predicting fatigue crack propagation rates based on crack closure computation under cyclic and time-dependent loading conditions.

\section{Finite element modelling}

\subsection{Specimen geometry}

In this study, a two-dimensional compact tension (CT) specimen was used to simulate creep-fatigue crack growth behavior. The study was conducted on a standard CT specimen of dimensions shown in Fig. 1. The selection of this specimen was done in accordance with the standard ASTM E2760 on testing methods for creep-fatigue crack growth [8]. CT specimens were machined and tested in the laboratory air under fatigue and creep-fatigue loading.
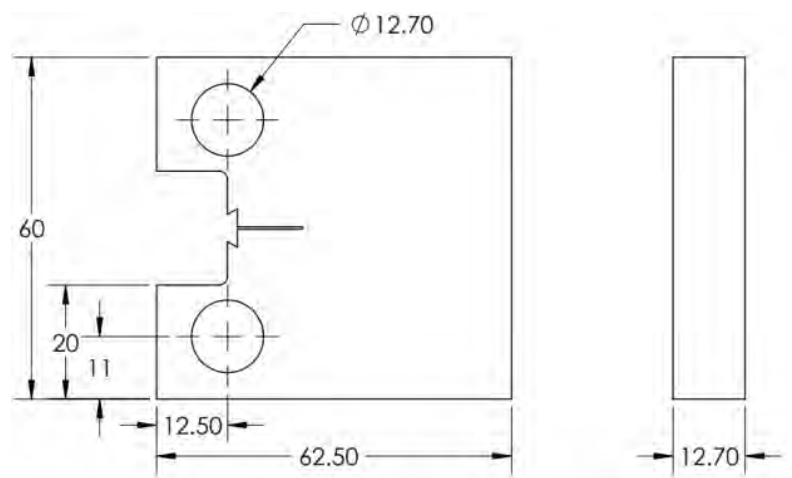

Fig. 1. C (T) geometry. Dimensions are in millimeters.

Initial crack length to width ratio was between 0.35 and 0.4. The starting $\Delta K$ evaluated ranged between 20 and $23 \mathrm{MPa} \sqrt{\mathrm{m}}$. The total crack growth simulated in this study corresponded to $2.0 \mathrm{~mm}$. Due to symmetry, only one half of the specimen was modelled in the finite element method. Loading of the CT specimen was imposed in the numerical model from a pin to the internal nodes of the hole through a multipoint constraint.

The numerical validation of this process entailed the computation of elastic load line displacements, stress intensity factors, $J$ integrals, and computation of the reaction forces at each node in the crack plane. Moreover, a common parameter used as a crack-tip driving force in creep and creep-fatigue crack growth experiments, the $C(t)$ contour integral parameter, was computed numerically with ABAQUS for stationary cracks. The prediction of the load line displacements, stress intensity factors and $C(t)$ contour integral were in good agreement with analytical computations from the theory of fracture mechanics at elevated temperatures.

\subsection{Meshing}

Two-dimensional plane-stress and plane-strain models of CT specimens were built in ABAQUS in order to simulate creep-fatigue crack growth behaviour. Four-node quadrilateral elements of type CPS4R for plane stress, and CPE4R for plane strain were employed for meshing. Reduced integration with hourglass control was employed to prevent shear locking. In order to capture the forward and reversed plastic zones around the crack tip, refined areas near the crack tip were required. The mesh of the two-dimensional CT specimen is shown in Fig.2.

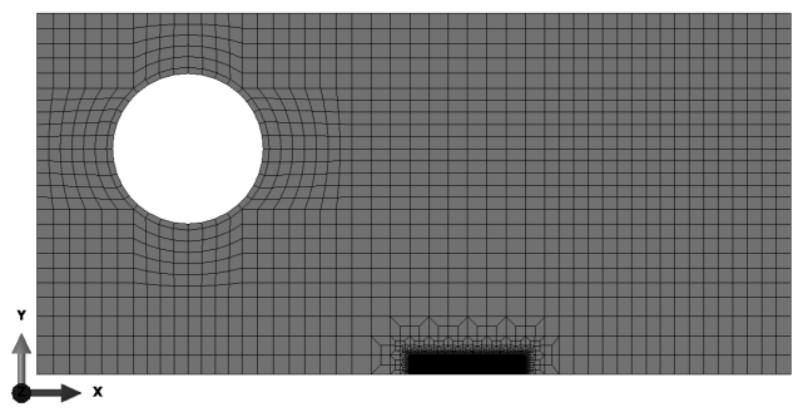

Fig. 2. 2D finite element mesh for CFCG and FCG predictions.

The magnified area near the crack tip with the largest mesh refinement is shown in Fig. 3. For this simulated specimen, the element size in the most refined area near the crack tip is $0.0125 \mathrm{~mm}$.

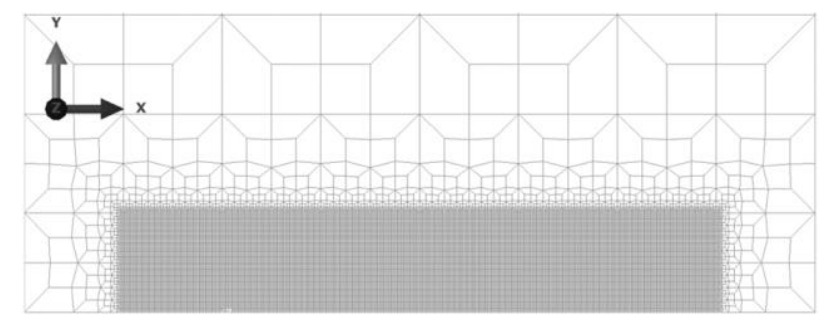

Fig. 3. Refined area around the crack tip.

\subsection{Boundary conditions}

Symmetry boundary conditions were applied to the finite element mesh. All nodes along the crack plane (from the 
crack tip to the right-hand side of the specimen) were constrained in the vertical direction $(Y=0)$. In addition, the load point displacement was constrained in the horizontal direction $(X=0)$. These boundary conditions are shown in Fig. 4.

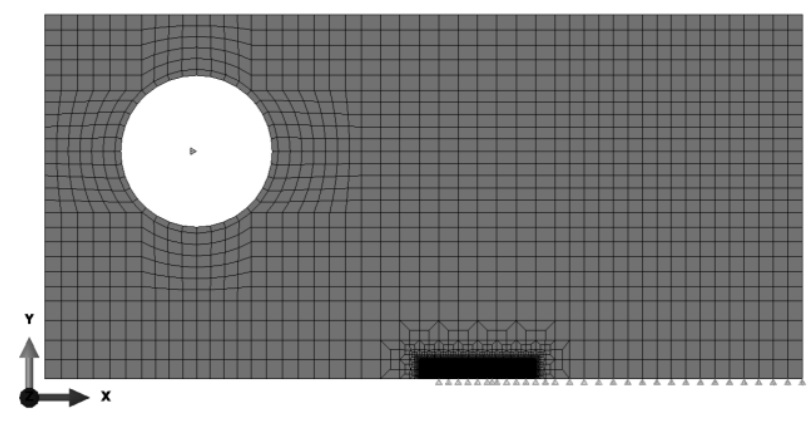

Fig. 4. Boundary conditions applied to the FE model.

\subsection{Loading waveform}

Trapezoidal waveforms simulated include a cyclic dependent and a time dependent step. In the first cyclic step, a tensile loading is applied during a specific time of loading, and a similar time is applied to the unloading step $\left(L_{T}, U_{T}\right)$. For the experiments on alloy 709 at $600^{\circ} \mathrm{C}$ and $700^{\circ} \mathrm{C}, L_{T}=U_{T}=0.25 \mathrm{~s}$. For the $\mathrm{P} 91625^{\circ} \mathrm{C}$ steel study, $L_{T}$ $=U_{T}=2 \mathrm{~s}$ [9]. In the second step, a time-dependent step with a hold time $t_{H}$ ranging from $60 \mathrm{~s}$ to $600 \mathrm{~s}$ according to experiment conditions was applied. A schematic of the waveform is illustrated in Fig.5. In the finite element simulations, crack advance was performed by a node release scheme. In the case of two-dimensional numerical simulations, two loading cycles were applied before node release. The procedure can be observed in Fig. 5 .

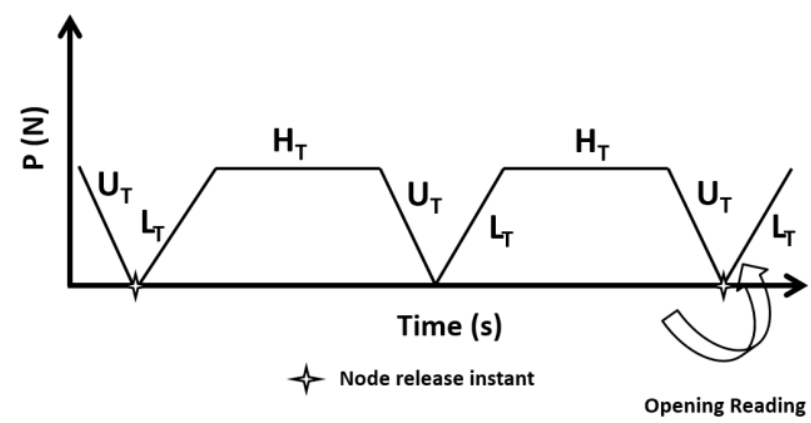

Fig. 5. Loading waveform and cycles applied before node release.

Crack propagation schemes to simulate crack closure are generally approached by the nodal release technique. The nodal release technique lacks physically realistic mechanism of crack growth; however, it is a very effective approach to simulate the plastic wake development with a steady state closure behaviour. In this study, the nodal release technique is adopted by node release at minimum load. Crack-tip opening stresses were computed with two methods, namely, the node displacement method and the stress method. The node displacement method defines as opening stress the remotely applied stress value that produces the first increment in vertical opening displacement for the last node to open behind the crack tip (most commonly, this is the first node behind the crack tip). The stress methods defines as opening stress the value of the remotely applied stress that causes the first increment in which all compressive stresses vanish for the nodes on the crack surface behind the crack tip. It was observed that both methods provide similar results. Therefore, the node displacement method was retained for its practicality.

\subsection{Material model}

Isotropic hardening of the material is considered by using an elastically-perfectly plastic material with the yield stress equal to the flow stress, which is calculated as the average between the yield and flow strengths. The choice of this material model is due to the early characterization stage of the material and the fact that low-cycle fatigue data is currently not available for elevated temperatures in Alloy 709. Moreover, in order to measure the impact of hardening and softening behavior of the material, the basic material models need to be considered first. The creep behavior was modeled with the strain-hardening version of Norton power law for secondary or steady state creep

$$
\stackrel{\overline{\bar{\varepsilon}}}{\mathrm{\varepsilon}}^{c r}=A \sigma_{e}^{n}
$$

\subsection{Creep-fatigue crack growth equations}

Paris et al. [10] proposed a relationship between fatigue crack growth rate $d a / d N$ and stress intensity factor range $\Delta \mathrm{K}$, of the form

$$
\frac{d a}{d N}=C \cdot \Delta K^{m}
$$

where $C$ and $m$ are material parameters. Stress intensity factor range $\Delta K$ is defined as:

$$
\Delta K=F\left(S_{\max }-S_{\min }\right) \sqrt{\pi a}
$$

where, $a$ is crack length, and $S_{\max }-S_{\min }$ is applied stress range. The term $F$ is a geometrical factor which depends on crack length and specimen geometry. In real cyclic loading conditions, the presence of repeated compressive loads are expected. The compressive residual stresses generated in front of the crack tip and between the crack surfaces decrease the crack-tip driving force to an effective value $\Delta K_{\text {eff }}$.

Fatigue crack propagation based on the crack closure concept states that crack growth rates are computed by the equation

$$
\frac{d a}{d N}=A \cdot\left(\Delta K_{e f f}\right)^{B}
$$

In a loading cycle, the effective part of the cycle is defined by $K_{\text {eff }}=K_{\max }-K_{o p}$, where crack opening levels are defined by either the corresponding stress intensity factors or stresses at which the crack tip begins to open during the 
loading cycle. $K_{o p}$ is defined as the stress intensity factor at which the crack starts to open. The effective stress intensity factor range in terms of the maximum stress intensity factor is given by

$$
\Delta K_{e f f}=K_{\max }-K_{o p}=K_{\max } \cdot\left(1-\left(\frac{K_{o p}}{K_{\max }}\right)\right)
$$

The effective stress range ratio or the closure factor can be written in terms of the normalizing opening loads $P_{\text {open }} / P_{\max }$

$$
U=\frac{\Delta K_{\text {eff }}}{\Delta K}=\frac{\left(1-\frac{P_{\text {open }}}{P_{\max }}\right)}{(1-R)}
$$

The total amount of crack growth in a creep-fatigue cycle is generally modelled as the added contribution of the cyclic dependent portion (loading and unloading parts of the trapezoidal waveform) and the tensile hold period part of the waveform.

$$
\left(\frac{d a}{d N}\right)=\left(\frac{d a}{d N}\right)_{L}+\left(\frac{d a}{d N}\right)_{H}
$$

Crack closure effect is considered by introducing the effective fatigue crack-tip driving force in the crack growth rate equation (4). The second contribution is the creep crack growth rate, which is given by:

$$
\left(\frac{d a}{d N}\right)_{H}=\left(\frac{d a}{d t}\right)_{H} \cdot t_{H}
$$

where the first term on the right hand side is computed based on the assumption that $K$ is a dominant parameter during crack growth

$$
\left(\frac{d a}{d t}\right)_{H}=A^{\prime} \cdot K_{M A X}^{B^{\prime}}
$$

\subsection{Model validation}

The numerical model has been validated first with respect to crack closure. Crack-closure measurements have been corroborated with two different numerical methods, namely strip yield modelling (SYM) and finite element (FE) model. The first validation corresponds to predictions performed for two-dimensional specimens in plane stress and plane strain conditions. Several studies [11-14] presented normalized opening stresses with respect to load ratio obtained from SYM. The comparison of results from the current finite element simulations with those from other studies [11-14] is given in Fig. 6. The higher dotted line represents plane stress, whereas the lower dotted line represents plane strain computations. These predictions have generally shown very good agreement with the values predicted for plane stress and plane strain when compared to the published data. Particularly, the normalized opening stress values for the load ratio ranging from 0 to 0.8 are satisfactory. It is important to point out that the future predictions of the CFCG of the present model are performed in the loading range between 0 and 0.7 . Therefore, good confidence of the predictions can be given to the proposed model.

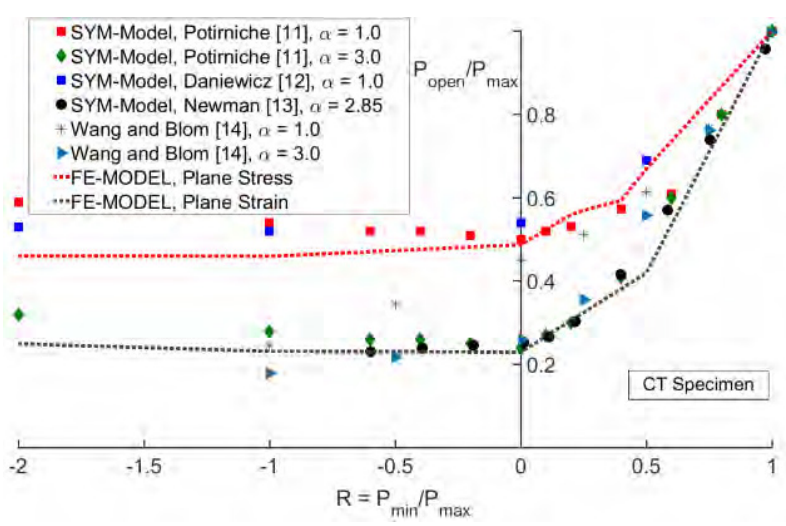

Fig. 6. Predicted normalized opening loads plotted as a function of the load ratio in compact tension specimens.

The second validation of predicted crack opening stresses was performed by comparing the current model results with finite element results of Solanki et al. [15]. Normalized opening stresses are presented in Fig. 7 as a function of the normalized element length with respect to the size of forward plastic zone. Normalized opening stress levels predicted are in good agreement when the same normalized stress intensity factor is introduced. Moreover, different conditions are evaluated to assess the model predictions at higher normalized stress intensity factors with different $a / W$ ratios.

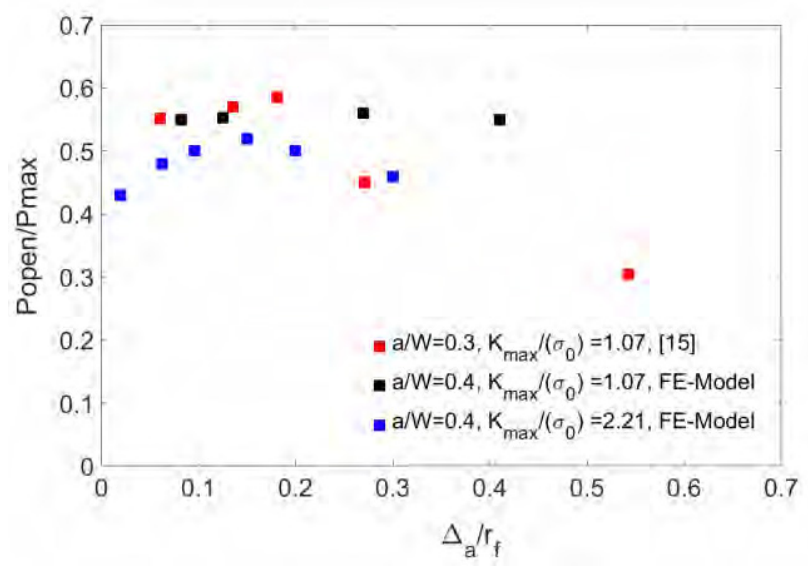

Fig. 7. Comparison of predicted opening stresses by this study and the finite element results of Solanki et al. [15] for the plane stress case.

\subsection{Experimental testing}

Fatigue and CFCG tests were conducted on Alloy 709 at $600^{\circ} \mathrm{C}$ and $700^{\circ} \mathrm{C}$ in laboratory air conditions. Applied hold times in the CFCG tests were $60 \mathrm{~s}$ and $600 \mathrm{~s}$, in a trapezoidal loading waveform. Specimens were precracked to the initial crack length using fatigue crack growth at room temperature. CT specimens were sidegrooved, with $4 \%$ of cross-section reduction on each side in order to keep crack growth planar. Experimental data of FCG and CFCG rates of Alloy 709 as a function of stress intensity factor range are presented in Fig 8. 


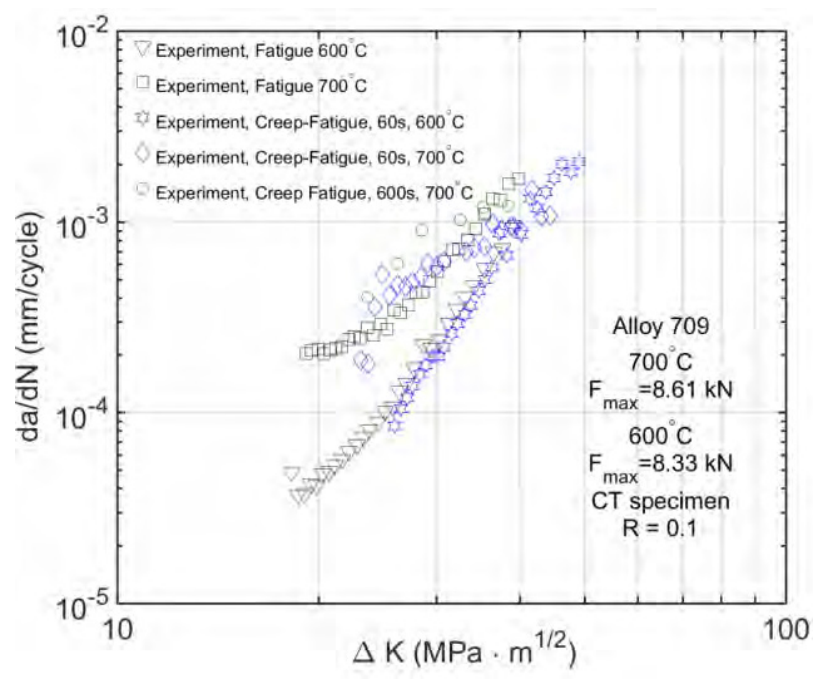

Fig. 8. Crack growth rate behavior of Alloy 709 .

Fatigue crack growth rates of modified $9 \mathrm{Cr}-1 \mathrm{Mo}$ steel at $625^{\circ} \mathrm{C}$ have been retrieved from a published study by Narasimhachary and A. Saxena [9] and they are shown in Fig. 9. In the next section, the modeling predictions of these results are predicted.

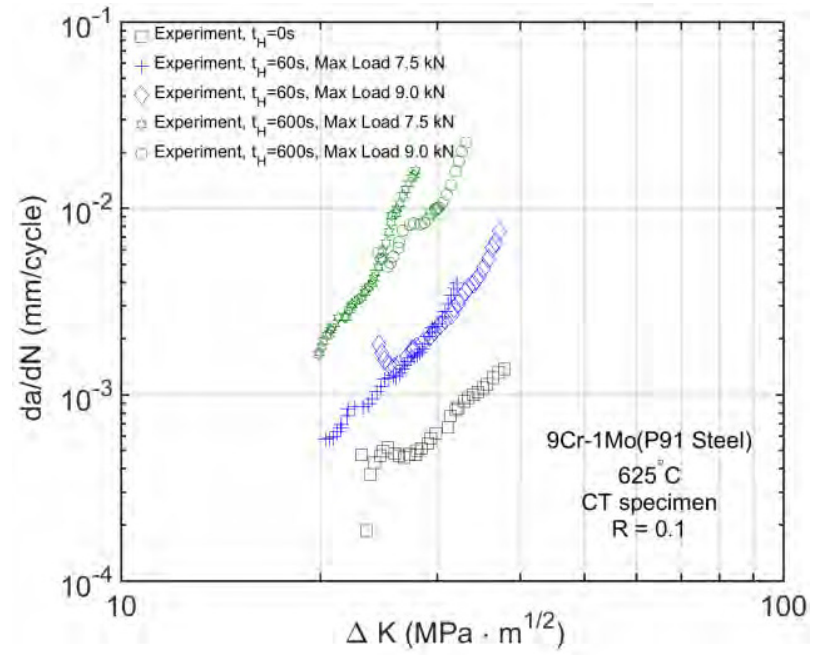

Fig. 9. Crack growth rate behavior of modified 9Cr-1Mo at $625^{\circ} \mathrm{C}$ according to Narasimhachary, and A. Saxena [9].

\section{Results}

In this section, the finite element predictions for the modified $9 \mathrm{Cr}-1 \mathrm{Mo}$ steel at $625^{\circ} \mathrm{C}$, and Alloy 709 at $600^{\circ} \mathrm{C}$ and $700^{\circ} \mathrm{C}$ are presented. First, the fatigue crack growth rates, as a function of $\Delta K$ with different hold times, namely, 60s and 600s, for 9Cr-1Mo steel are discussed. Narasimhachary and Saxena [9] reported significant contribution of time dependent crack growth to the total crack growth rate for creep-fatigue loading with various hold times and maximum applied loads. For this reason, the first set of CFCG rates for hold times of $60 \mathrm{~s}$ and $600 \mathrm{~s}$, in CT specimens with initial crack length $(a / W)=0.4$ and maximum load $\mathrm{F}_{\max }=7.5 \mathrm{kN}$ are presented. The finite element predictions are carried out by incorporating the normalized opening stress values computed with ABAQUS and the corresponding constants that allow the computations of total crack growth rate due to the time dependent deformation. The variation of the opening loads with hold time predicted by the finite element simulations is shown in Fig. 10. The material properties used in this study were: (a) Norton creep constants, $A=$ $9.53 \cdot 10^{-21} \mathrm{MPa}^{-\mathrm{n}} \mathrm{h}^{-1}$ and $n=8.24$, (b) mechanical properties, $E=125 \mathrm{GPa}, \sigma_{0}=325.1 \mathrm{MPa}, \sigma_{U T S}=343.7$ $\mathrm{MPa}$ at $625^{\circ} \mathrm{C}$ [9]. The material constants used in the fatigue and fatigue crack growth equations (4) and (9) were $A=8.50 \cdot 10^{-8}, B=3.0$, and $A^{\prime}=1.30 \cdot 10^{-7}, B^{\prime}=3.5$, respectively.

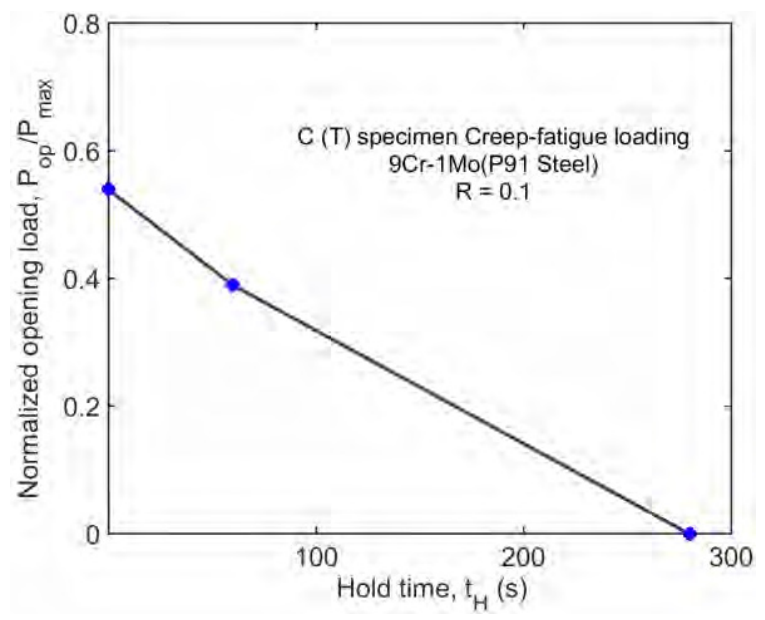

Fig. 10. Normalized opening loads as a function of hold time for $F_{\max }=7.5 \mathrm{KN}$.

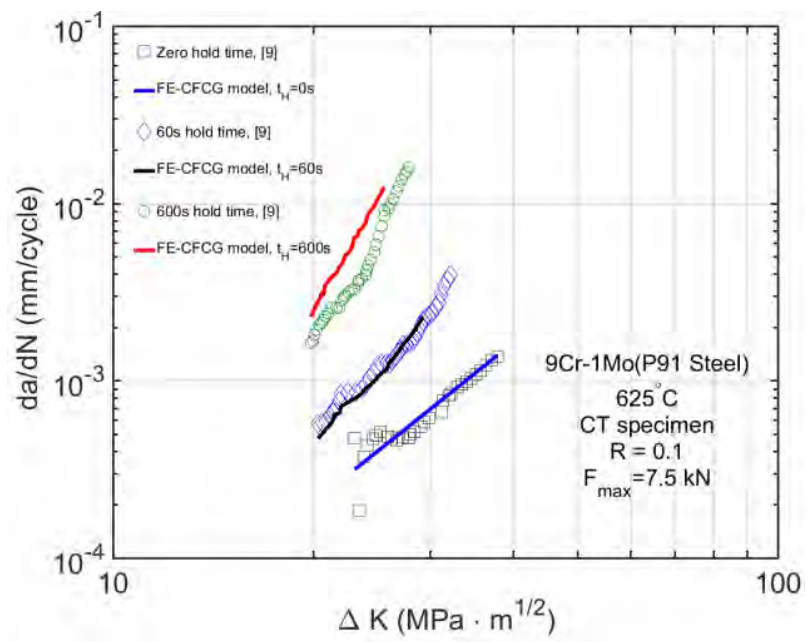

Fig. 11. Comparison between the current finite element predictions and experimental data ([9]) of creep-fatigue crack growth rate for different hold times in modified $9 \mathrm{Cr}-1 \mathrm{Mo}$ steel at $625^{\circ} \mathrm{C}$ at $F_{\max }=7.5 \mathrm{KN}$.

Fig. 11 shows the model prediction for hold times of $60 \mathrm{~s}$ and 600s. Fatigue crack growth rates per cycle predicted for 600 s show a slight over-prediction. This behavior is due to the fact that the fatigue crack growth rate per cycle is predicting using $\Delta K$ values and coefficients $A$ and $B$ that satisfy the fatigue crack growth rates corresponding to a higher load. More precisely, the fatigue crack growth rate employed to make the 
predictions for $7.5 \mathrm{kN}$ correspond to a growth rate generated by a load of $9 \mathrm{kN}$. In contrast, when the adequate fatigue crack growth rate data is employed to make the computations, more accurate predictions can be made by the model.

These predictions are shown in Fig. 12 for 60 s and 600 s when a maximum load of $9 \mathrm{kN}$ load is applied. It can be noticed that the predictions are in good agreement with the experimental data. The corresponding normalized opening loads employed in these computations are given in Figure 13. The material properties used in this study were: (a) Norton creep constants, $A=9.53 \cdot 10^{-21} \mathrm{MPa}^{-\mathrm{n}} \mathrm{h}^{-1}$ and $n=8.24$, (b) Material properties, $E=125 \mathrm{GPa}, \sigma_{0}=$ 325.1 MPa, $\sigma_{U T S}=343.7 \mathrm{MPa}$ at $625^{\circ} \mathrm{C}$ [9]. The material constants used in the fatigue and fatigue crack growth equations (4 and 9), were $A=1.95 \cdot 10^{-7}, B=3.0$, and $A^{\prime}=$ $2.50 \cdot 10^{-7}, B^{\prime}=3.4$, respectively.

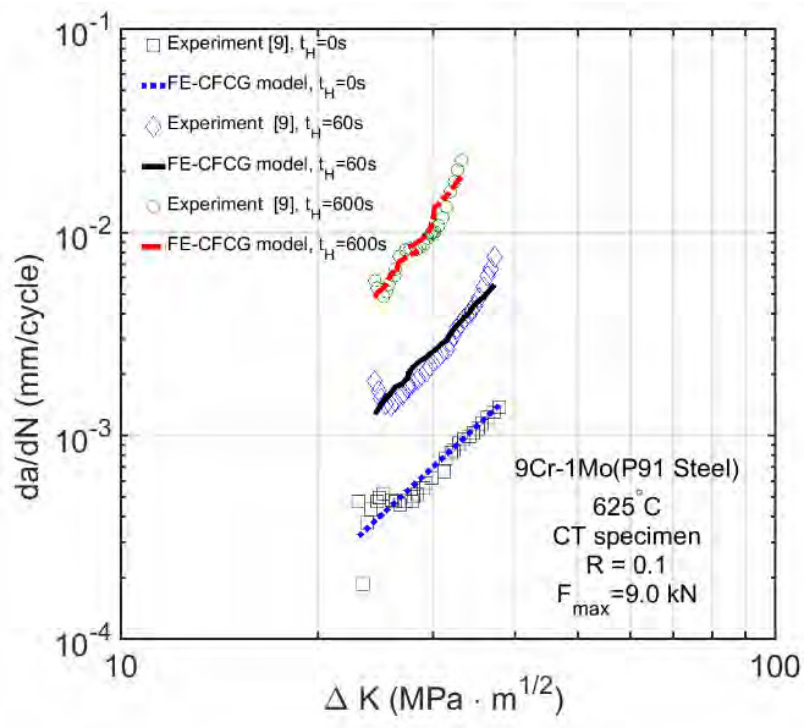

Fig. 12. Comparison between the current finite element predictions and experimental data ([9]) of creep-fatigue crack growth rate for different hold times in modified 9Cr-1Mo steel at $625^{\circ} \mathrm{C}$ at $F_{\max }=9.0 \mathrm{KN}$.

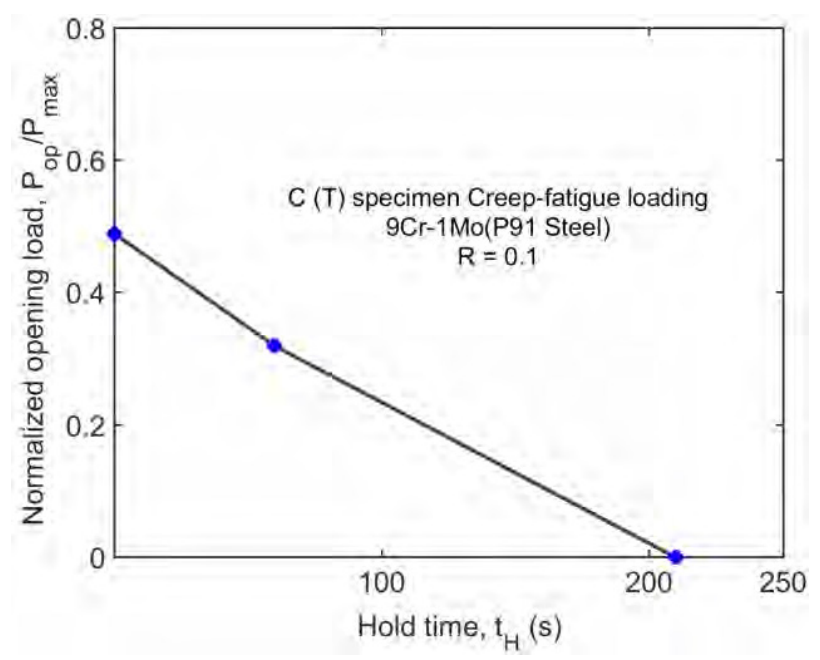

Fig. 13. Normalized opening loads as a function of hold time for $F_{\max }=9.0 \mathrm{KN}$.

Next, predictions for alloy 709 are presented. These predictions are shown in Fig. 14. From the performed finite element simulations, it was observed that opening loads for Alloy 709 do not change with increasing hold times. Therefore, it can be concluded that there is no influence of the normalized opening load in the predictions of the CFCG rate in Alloy 709. In Fig. 14, crack growth rates per cycle predicted for 600 s shows a slight over-prediction for lower values of $\Delta K$. However, between $\Delta K$ values of 27 and $35 \mathrm{MPa} V_{\mathrm{m}}$, the computational predictions are in good agreement with experimental data. The material properties used in this simulations for Alloy 709 were: (a) Norton creep constants, $A=4.96 \cdot 10^{-18} \mathrm{MPa}^{-\mathrm{n}} \mathrm{h}^{-1}$ and $n=5.9$, (b) Material properties, $E=148.9 \mathrm{GPa}, \sigma_{0}=178 \mathrm{MPa}, \sigma_{U T S}=$ $449 \mathrm{MPa}$ at $700{ }^{\circ} \mathrm{C}$. The normalized opening stress predicted value is 0.62 . The material constants used in the fatigue and fatigue crack growth equations (4) and (9) were $A=2.0 \cdot 10^{-7}, B=2.98$, and $A^{\prime}=1.50 \cdot 10^{-7}, B^{\prime}=3.2$, respectively.

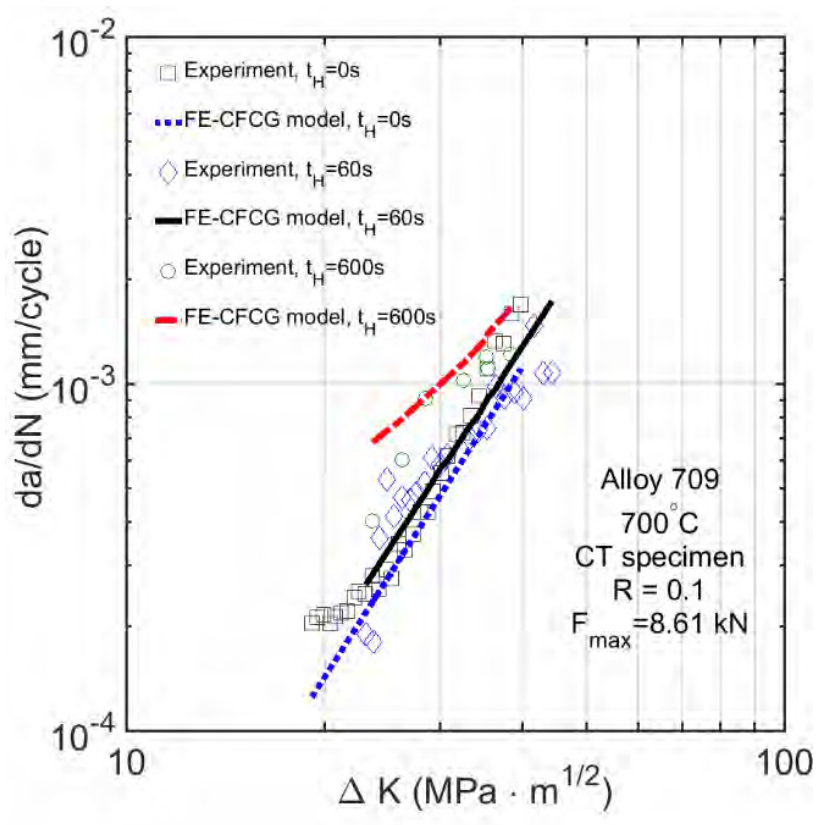

Fig. 14. Comparison between computational prediction and experimental measurements of creep-fatigue crack growth rates at various hold times in Alloy 709 at $700^{\circ} \mathrm{C}$.

Fatigue crack growth rates in Alloy $709 \mathrm{CT}$ specimens were experimentally measured at $600^{\circ} \mathrm{C}$ and compared with finite element modeling predictions. This comparison is illustrated in Fig. 15. Only predictions for 60s hold time were carried out, as experimental data for longer hold times was not available given the excessively long testing time that would have been needed for creep testing at $600^{\circ} \mathrm{C}$.

Overall, model predictions compare satisfactorily with the experimental data at both temperatures of $600^{\circ} \mathrm{C}$ and $700^{\circ} \mathrm{C}$. Material properties used in this prediction were: (a) Norton creep constants, $A=2.83 \cdot 10^{-22} \mathrm{MPa}^{-\mathrm{n}} \mathrm{h}^{-1}$ and $n$ $=6.7,(\mathrm{~b})$ The material properties, $\mathrm{E}=155.8 \mathrm{GPa}, \sigma_{0}=$ 191.4 $\mathrm{MPa}, \sigma_{U T S}=583 \mathrm{MPa}$ at $600{ }^{\circ} \mathrm{C}$. The predicted normalized opening stress value was found to be 0.65 . The material constants used in the fatigue and fatigue crack growth equations (4) and (9) were $A=9.0 \cdot 10^{-9}, B=$ 4.26 , and $A^{\prime}=1.50 \cdot 10^{-7}, B^{\prime}=3.2$, respectively. 


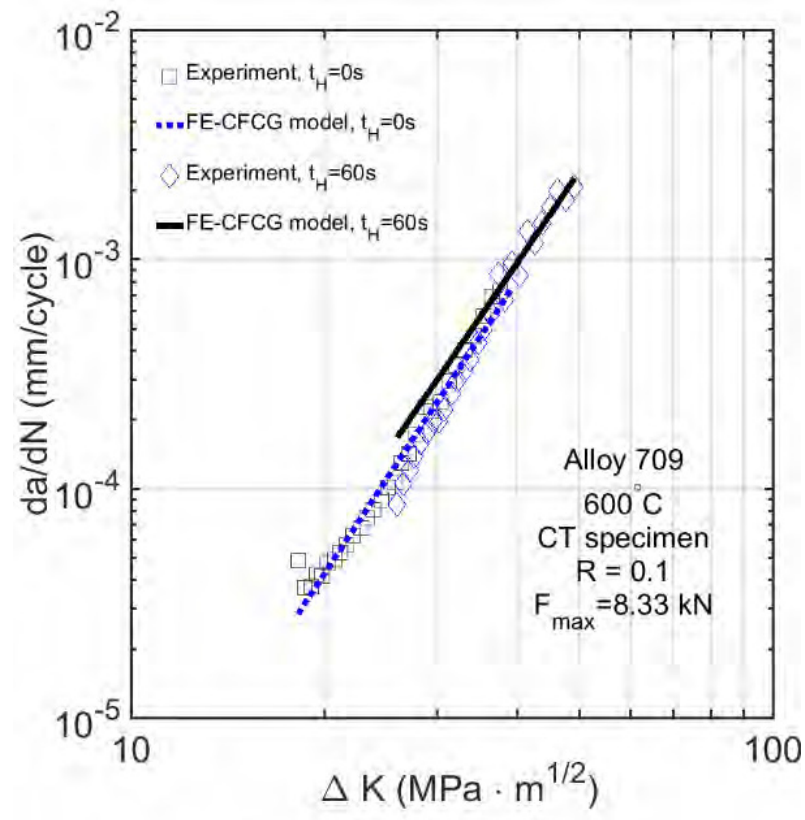

Fig. 15. Comparison between computational prediction and experimental measurements of creep-fatigue crack growth rates at various hold times in Alloy 709 at $600^{\circ} \mathrm{C}$.

\section{Conclusions}

A two-dimensional finite element model was proposed to predict experimental creep-fatigue crack growth rates in modified 9Cr-1Mo and Alloy 709 steels. Plasticityinduced crack closure simulations in modified $9 \mathrm{Cr}-1 \mathrm{Mo}$ have shown a decrease of the opening stress with increasing hold time, whereas in Alloy 709 this influence does not exist. While creep-fatigue interaction in modified 9-Cr-1Mo are significant, in Alloy 709 they are almost inexistent. This can be attributed to high resistance to creep deformation of Alloy 709. The proposed model provides good agreement with experimental data, independently of the computational method used to measure the opening levels, i.e. the nodal displacement or contact stress method. In these simulations, the number of cycles between releases have an effect on the computed opening stresses but this is due primarily to the applied hold times. The proposed finite element modeling can account for creep-fatigue interactions on creep-fatigue crack growth in alloys at high temperatures, and it can be reliably used to make life prediction estimates in structural components.

The funding support of this work by the U.S. Department of Energy under the Nuclear Energy University Program (Grant DE-NE0008443) work is gratefully acknowledged.

\section{References}

1. T.L. Sham, K. Natesan, Code Qualification Plan for an Advanced Austenitic Stainless Steel, Alloy 709, for Sodium Fast Reactors Structural Applications, International Conference FR17 (2017)
2. J.T. Busby, Candidate Developmental Alloys for Improved Structural Materials for Advanced Fast Reactors. ORNL/GNEP/LTR-2008-023. 2008.

3. W. Elber, Eng Fract Mech, 2, 37-45 (1970)

4. S. Suresh, Fatigue of Materials (Cambridge University Press, 1998)

5. P.F.P. de Matos, D. Nowell, Eng Fract Mech, 75, 2087-2114 (2008)

6. H. Sehitoglu, W. Sun, Eng Fract Mech, 33, 371-388 (1989)

7. S. Pommier, Fatigue Fract. Eng. Mater. Struct, 19, 1117-1128 (1996)

8. ASTM Standard E2760-10, (ASTM International, West Conshohocken, PA, 2010)

9. S.B. Narasimhachary, A. Saxena, Int. J. Fatigue, 56, 106-113 (2013).

10. PC. Paris, F. Erdogan, J Basic Eng, 85, 528-534 (1960)

11. G.P. Potirniche, 12th International Fatigue Congress (2018) (to be published)

12. S.R. Daniewicz, J.A. Colins, D.R. Houser, Fatigue, 16 (1994)

13. J.C. Newman, Jr., Design of Fatigue and Fracture resistant Structures, ASTM STP 761 (1982)

14. G.S.Wang, F. Blom, Eng Fract Mech, 40, 507-533 (1991)

15. K. Solanki, S.R. Daniewicz, J.C. Newman Jr, Eng Fract Mech, 70, 1475-1489 (2003) 